•编者按・

\title{
世界自然遗产既要加强保护也要适度利用
}

\author{
马克平 ${ }^{*}$
}

(中国科学院植物研究所植被与环境变化国家重点实验室, 北京 100093)

\section{Conservation of world natural heritage should be ensured and its con- tribution to local sustainable development promoted}

\author{
Keping $\mathrm{Ma}^{*}$ \\ State Key Laboratory of Vegetation and Environmental Change, Institute of Botany, Chinese Academy of Sciences, Beijing 100093
}

第40届世界遗产大会于2016年7月在土耳其伊 斯坦布尔召开, 湖北神农架和广西花山岩画被正式 列入世界自然和文化遗产，使得我国的世界遗产地 达到 50 处, 位列世界第二, 与排在第一位的意大利 仅差一处。截至目前, 全球的世界遗产地已达 1,052 处, 其中自然遗产地203处, 文化遗产地 814 处, 双 遗产地35处, 分布在 165 个缔约方 (http://whc.unesco. $\mathrm{org} / \mathrm{en} / \mathrm{list}$ )。我国的世界自然遗产地达到15处(其中 4 处为世界自然和文化双遗产, 附录 1 ), 占全球的 $6.3 \%$, 属于比例较高的国家。在这些世界自然遗产 地中, 有 10 个是生物多样性保护的重要基地, 尤以 四川大熊猫栖息地、武夷山常绿阔叶林、神农架植 物与植被、新疆天山的果树种质资源等具有很高的 保护价值; 其他世界自然遗产地包括地质地貌类型 的遗产地，如南方喀斯特和丹霞地貌等，都拥有丰 富而独具特色的生物多样性(Luo et al, 2016), 应该 加强保护。

1972年11月联合国教科文组织(UNESCO)第 17 届大会通过了由世界自然保护联盟(IUCN)起草的 《保护世界文化和自然遗产公约》(以下简称《公 约》), 目前已经有192个缔约方 (http://whc.unesco. org/en/list/)。根据该公约的规定，设立了世界遗产委 员会(World Heritage Committee)。该委员会由 21 个 缔约方组成, 负责推动《公约》的实施。世界遗产 委员会主席团负责委员会的日常工作。世界遗产大 会每年举行一次, 主要议题是决定哪些遗产可以进 入《世界遗产名录》, 对已列入名录的世界遗产的 保护工作进行监督指导, 根据需要修改《保护世界
文化和自然遗产公约操作指南》。《公约》述及的 世界遗产包括4种类型: 文化遗产、自然遗产、文化 和自然混合遗产(双遗产)和文化景观。

我国全国人民代表大会常务委员会1985年11 月22日批准了《保护世界文化和自然遗产公约》, 标 志着我国正式成为缔约方。由于遗产资源丰富和政 府卓有成效的申报工作，我国的世界遗产事业在过 去的 20 年里得到迅猛发展, 已居世界第二位, 跃居 第一也是指日可待的事情。发展的动力何在? 利用 世界遗产地平台，让我国的宝贵资源得到全球广泛 认可应该是主要动因; 加入世界遗产网络, 采取更 加有效和严格的保护措施也是动因之一(对于有些 遗产地而言, 也许是主要动因); 借此发展旅游产业 振兴地方经济是申报的重要动力, 甚至是相当一部 分地方政府的主要考虑。其实, 不仅中国的地方政 府申报世界遗产的热情主要不是源于加强保护, 这 在其他国家的世界自然遗产地中也有一定程度的 反映，尽管这是《公约》的宗旨所在。

Conradin等(2015)对分布在不同地区的 128 个世 界自然遗产地的现状和作用做过比较全面的调查 分析。结果显示, 世界自然遗产管理者和相关人员 对自然遗产的定位正在发生变化, 从最初的严格保 护，到现在的综合管理，包括对旅游业和当地社会 经济可持续发展的贡献。尽管《公约》的宗旨仍然 表述为“为集体保护具有突出普遍价值的文化遗产 和自然遗产建立一个依据现代科学方法组织的永 久性的有效制度”。关键词是保护，而非可持续利 用。然而, 不仅是已经列入《世界遗产名录》的自

* 通讯作者 Author for correspondence. E-mail: kpma@ibcas.ac.cn 
然遗产地在改变自己的定位，《公约》本身也在逐 步改变自己的定位，尽管公约宗旨的描述还没有修 改。例如，1992年世界遗产委员会第16次会议决定 增加文化景观为世界遗产的新类型, 以发挥其在维 护生态系统过程和生物多样性中的重要作用 (http://whc.unesco.org/archive/1992/whc-92-conf00212e.pdf)。这说明UNESCO在改变绝对保护的理念, 承认人类活动在保护世界遗产中的积极作用。2002 年世界遗产委员会第26次会议通过的布达佩斯宣 言中强调了世界遗产地对可持续发展做出贡献的 潜力; 2010年和2012年的世界遗产委员会都在讨论 将可持续发展作为公约的目的之一(Conradin et al, 2015)。UNESCO对世界遗产地开展旅游采取积极的 态度，2012年11月开始了“世界遗产与可持续旅游 (World Heritage and Sustainable Tourism)" 项目, 其 愿景是让所有利益相关者共同承担责任，以保护世 界文化和自然遗产的突出普遍价值, 并通过适度的 旅游管理促进可持续发展 (http://whc.unesco.org/ en/tourism/)。总而言之, 世界自然遗产的管理首先要 重视保护，同时也要考虑适度旅游和当地的可持续 发展。这应该是国内外和业界的共识。相信这样的 理念在不久的将来会体现在《公约》的文本中。

关于我国世界自然遗产地的申报和管理，目前 尚存在以下几个方面的问题:

(1)重个案受理轻顶层设计。从目前我国自然遗 产的申报情况看, 多数都是地方政府自由申报后国 务院主管部门按照程序受理, 缺乏比较全面的国家 水平的顶层设计和规划方案, 随意性比较大。主管 部门应该组织编制中国自然遗产发展规划, 按照 《公约》和“申报指南”的要求, 对具有突出普遍价 值的区域和类型进行系统梳理，做好规划，并鼓励 地方政府积极做好申报的准备工作。地方的积极性 是十分重要的。我国自然遗产地主管部门的负责人 经常强调三点: 具有突出普遍价值、地方政府申报 的积极性和成熟的申报文本。后两点都与地方政府 相关。再者, 在考虑申报优先项目(世界自然遗产预 备清单)时，应考虑地区和类型的平衡，选择具有突
出普遍价值但已列入世界自然遗产名录比较少的 地区或类型申报，以提高成功的机会。

(2)重申报过程轻规范管理。地方政府申报世界 自然遗产主要的动因经常是发展旅游业以促进当 地经济社会的发展。一旦申报成功，则多对保护管 理重视不够，而关注更多的是旅游人数的增减和旅 游设施的规划建设，这种倾向应引起有关部门的重 视。主管部门应该建立规范的管理制度，经常性地 督导检查，并鼓励社会各界参与监督，使我国世界 自然遗产地在总体规划和法律法规的制约下健康 发展。

(3)重静态调查轻动态监测。为了编制申报文本, 编写团队会对申报地开展比较全面的调查和相关 文献资料的分析整理。虽然申报文本的规划部分都 有关于后期监测的描述，但大多执行得不理想。不 仅点上的监测大多不到位, 全国水平的监测更是缺 位。目前的遥感手段完全可以满足对自然遗产地管 理和保护对象的监测需要, 症结在落实。建议主管 部门重视这项工作，尽快建立监测体系和相关的运 行管理机制。

(4)重境内遴选轻跨界意识。目前为止，我国的 世界自然遗产地申报很少涉及跨国境的项目。这与 我们幅员辽阔、资源丰富直接相关，也与申报项目 由地方政府首先提出的程序有关，无可厚非。但近 年来一些新的动向应引起有关部门注意, 需要适当 调整工作思路。而且，不仅应重视陆地自然遗产地， 还应该重视海洋类型自然遗产地的遴选和申报，当 前应该特别关注东海海域及周边国家的申报动向, 采取积极的应对措施。

\section{参考文献}

Conradin K, Engesser M, Wiesmann U (2015) Four decades of World Natural Heritage - how changing protected area values influence the UNESCO label. Journal of the Geographical Society of Berlin, 146, 34-46.

Luo ZH, Tang SH, Jiang ZG, Chen J, Fang HX, Li CW (2016) Conservation of terrestrial vertebrates in a global hotspot of karst area in southwestern China. Scientific Reports, 6, doi: $10.1038 /$ srep25717.

\section{附录 Supplementary Material}

附录1 中国世界遗产名录(截至2016年7月)

Appendix 1 World heritage list of China http://www.biodiversity-science.net/fileup/PDF/2016240-1.pdf 
附录 1 中国世界遗产名录(截至 2016 年 7 月). 世界自然遗产地; 世界文化遗产地; 世界自然和文 化双遗产地）

Appendix 1 World heritage list of China. Natural site; Cultural site; Mixed site.

1 山东泰山: 泰山（山东泰安市）、岱庙（山东泰安市）、灵岩寺（山东济南市）

2 甘肃敦煌莫高窟

3 周口店北京人遗址

4 长城

5 陕西秦始皇陵及兵马俑

6 明清皇宫: 北京故宫 沈阳故宫（辽宁）

7 安徽黄山

8 四川黄龙国家级名胜区

9 湖南武陵源国家级名胜区

10 四川九寨沟国家级名胜区

11 湖北武当山古建筑群

12 山东曲阜的孔庙、孔府及孔林

13 河北承德避暑山庄及周围寺庙

14 拉萨布达拉宫历史建筑群（大昭寺、罗布林卡）

15 四川峨眉山一乐山风景名胜区

16 江西庐山风景名胜区

17 苏州古典园林

18 山西平遥古城

19 云南丽江古城

20 北京天坛

21 北京弫和园

22 福建省武夷山

23 重庆大足石刻

24 安徽古村落: 西递、宏村

25 明清皇家陵寝：明显陵（湖北钟祥市）、清东陵（河北遵化市）、清西陵（河北易 县）、明孝陵（江苏南京市）、明十三陵（北京昌平区）、盛京三陵（辽宁沈阳市）

26 河南洛阳龙门石窟

27 四川青城山和都江堰

28 大同云冈石窟

29 云南“三江并流”自然景观

30 吉林高句丽王城、王陵及贵族墓葬 
31 澳门历史城区

32 四川大熊猫栖息地

33 中国安阳殷墟

34 中国南方喀斯特

35 开平碉楼与古村落

36 福建土楼

37 江西三清山

38 山西五台山

39 河南登封“天地之中”古建筑群（少林寺、东汉三阙）

40 湖南峎山、广东丹霞山、福建泰宁、贵州赤水、江西龙虎山、浙江江郎山丹霞地貌

41 杭州西湖文化景观

42 元上都遗址

43 澄江化石地

44 新疆天山

45 红河哈尼梯田文化景观

46 中国大运河：隋唐大运河、京杭大运河和浙东运河

47 丝绸之路: 长安-天山廊道路网

48 湖南、贵州、湖北土司遗址

49 广西左江花山岩画

50 湖北神农架 